\title{
Autogenous Demineralized Dentin Matrix Graft for Socket Preservation
}

\section{Mahadeepa Kar ${ }^{1}$, Ashish Gupta ${ }^{2 *}$, N Srinath ${ }^{3}$, Umashankar DN ${ }^{4}$, Mahesh Kumar $^{5}$ and Ankita Dahiya ${ }^{6}$}

${ }^{1}$ Intern, Department of Head and Neck Oncology, Vedant Hospital, Thane, Mumbai, India

${ }^{2}$ Intern, Rajiv Gandhi Cancer and Research Hospital, Rohini, New Delhi, India

${ }^{3}$ Professor and HOD, Department of Oral and Maxillofacial Surgery and Oral

Implantology, Krishnadevaraya College of Dental Sciences, Bangalore, Karnataka,

India

${ }^{4}$ Professor, Department of Oral and Maxillofacial Surgery and Oral Implantology,

Krishnadevaraya College of Dental Sciences, Bangalore, Karnataka, India

${ }^{5}$ Professor and HOD, Department of Oral and Maxillofacial Surgery and Oral

Implantology, Sri Siddharta Dental College, Tumkur, Karnataka, India

${ }^{6}$ Resident, Department of Oral and Maxillofacial Surgery and Oral Implantology,

Krishnadevaraya College of Dental Sciences, Bangalore, Karnataka, India

*Corresponding Author: Ashish Gupta, Intern, Rajiv Gandhi Cancer and Research

Hospital, Rohini, New Delhi, India.
Received: March 15, 2021

Published: March 27, 2021

(C) All rights are reserved by Ashish Gupta., et al.

\section{Abstract}

Aims: The study aims to evaluate the efficacy of autogenous tooth as bone graft material in the extraction socket and also to assess the potential use of the material as an alternative for autologous bone and other graft materials.

Methods: 30 patients requiring extraction of bilateral mandibular third molars were included. It was a split-mouth technique; one side was taken up as the control group and the other side as the study group. Postoperative pain and bone healing were assessed at 3 and 6 months follow-ups post-operatively.

Results: The intensity of pain was higher in 24 hours as compared to 7 days in the study and control group but it was statistically not significant $(\mathrm{p}>0.05)$. The intensity of swelling was higher in 24 hours as compared to 7 days in the study group which was statistically significant $(\mathrm{p}<0.05)$. In the study group, it was 127.97 and 120.5 was in the control group. The study group was higher as compared to the control group and it was statistically significant $(\mathrm{p}<0.05)$.

Conclusion: Significant improvement in wound healing and increase in bone density highlights the use of autogenous tooth as a graft material in inducing and accelerating hard tissue regeneration following tooth extraction. The usage of the tooth as a graft material is simple, cost-effective, and requires no special armamentarium and infrastructure for preparation.

Keywords: Autogenous Tooth; Bone Healing; Demineralised Dentin; Socket Preservation; Bone Density 


\section{Introduction}

Post extraction bone loss is a physiological phenomenon that leads to alveolar remolding and formation of bone within the socket. However, studies have documented that the bone volume following extraction decreases by $50 \%$ within 12 months, and twothird of this resorption takes place during the first 3 months after extraction [1]. Therefore maintaining 3-dimensional alveolar bone volume is required for ideal esthetic and functional implant-supported restorations.

Horowitz., et al. [1] stated that less ridge resorption occurs when alveolar ridge preservation procedures are used as compared to leaving fresh alveolar sockets without placing any graft material. Autogenous bone, allogenic bone, xenogenic bone, and alloplastic materials are bone graft materials that are used in dental clinics. According to bone healing mechanism, they can be categorized into materials that induce osteogenesis, osteoinduction and osteoconduction. Among the many different types of bone graft materials, autogenous bone is the most ideal since it is capable of osteogenesis, osteoinduction, and osteoconduction. Its advantage is rapid healing time without immune rejection [2]. However, the biggest shortcoming is that the amount harvested is limited, bone resorption after grafting is unavoidable and a second defect is generated in the donor area [3].

An ideal bone graft material should stabilize the blood clot, provide a biomechanical scaffold for cell migration, proliferation and differentiation; contain functional proteins and peptides, such as growth factors; and exhibit appropriate resorption and remodeling during new bone formation [4]. In 2003, Murata., et al. [3] first presented the idea of using human dentin as bone graft material in the same patient to regenerate new bone. The tooth is increasingly attracting attention as a material for alveolar bone regeneration. It is composed of an organic matrix and an inorganic reinforcing phase of hydroxyapatite. Radial arrays of dense Type I collagen fibrils, which account for $90 \%$ of the organic matrix and $10 \%$ of noncollagenous acidic proteins play an important part in calcification. The chemical composition of dentin is very similar to that of bone. The inorganic content is $70-75 \%$, organic content $20 \%$ and water content $10 \%$. In alveolar bone, these components are present in proportions of $65 \%, 25 \%$, and $10 \%$ respectively [5]. Moreover, the tooth has a much lower fat content and no marrow compared to bone, which makes it easier to be changed into graft material [6].
Aim of the Study

The present prospective study aims to evaluate the efficacy of autogenous tooth as bone graft material in the extraction socket and also to assess the potential use of the material as an alternative for autologous bone and other graft materials. This study stands different and unique from the previous studies because it advocates the use of graft material that is cost-effective and easily accessible. Bone healing and maintenance 3-D bone alveolar volume still holds a challenge in the posterior maxilla for implant rehabilitation. Making use of easily available dentine from the extracted tooth takes us few steps closer to "search of an ideal bone graft".

\section{Materials and Methods}

The present study was conducted on 30 patients visiting the Department of Oral and Maxillofacial Surgery in a dental institution. All the patients were informed about the study and consent was taken for the same. Routine radiological examinations were done 3 months and 6 months postoperatively. Patients who were having a sound tooth, who were having impacted teeth with no obvious pathology who were in the age group of 18 - 40 years, and who were willing to participate were included in the study. Patients having any odontogenic infection, pregnant women, medically compromised, chronic smokers and who were not willing to participate were excluded from the study. The surgical procedure included surgical disimpaction of the tooth, followed by crushing into small particles and placement in $0.3 \mathrm{~N}$ nitric acid for 20 minutes. Rinsed with saline and treated with $30 \%$ ethanol and $0.5 \mathrm{M} \mathrm{NaOH}$. The graft was rinsed thoroughly with saline and placed into the study site. Clinical assessment and radiological evaluation of the study and control site were done postoperatively on the day of surgery, on the $7^{\text {th }}$ day and after 3 months and 6 months respectively. After the extraction, primary closure was done in the $1^{\text {st }}$ appointment. Patients had been recalled after 7 days for extraction of the third molar of the contralateral side. In the $2^{\text {nd }}$ appointment, surgical removal of mandibular $3^{\text {rd }}$ molar of the contralateral side was carried out in the same manner as done previously. The graft material which had been processed from the extracted tooth in the previous appointment was packed into the extraction socket of the contralateral side, followed by primary closure of the site by 3-0 black braided silk suture material. Clinical assessment and radiological evaluation of the study and control site were done postoperatively on the day of surgery, on the $7^{\text {th }}$ day, and after 3 months and 6 months respectively. 


\section{Statistical analysis}

The data was entered and analyzed using the Statistical Package for Social Sciences (SPSS) for Windows 26.0. (SPSS, Inc. Chicago, Illinois) Confidence intervals were set at 95\%, and a p-value $\leq$ of 0.05 was considered statistically significant. Number and Percentage were calculated for discrete data. Mann-Whitney $U$ test was used to analyze the difference between the medians of different data sets.

\section{Results}

In 24 hours intensity of pain was 5.37 in the study group and 4.87 in the control group ( $p=0.18$ ). After 7 days, the intensity was 1.73 in the study group and 1.5 in the control group ( $p=0.15)$. In the $3^{\text {rd }}$ and $6^{\text {th }}$ months, there was no pain. The intensity of pain was higher in 24 hours as compared to 7 days in the study and control group but it was statistically not significant ( $p>0.05$ ) (Table 1). Comparison of mean swelling intensity scores between the study and control group in relation to the duration was assessed. In 24 hours, the intensity of swelling was 0.33 in the study group and 0.07 in the control group $(p=0.001)$ whereas on the $7^{\text {th }}$ day intensity was 0.07 in the study group and no intensity was seen in the control group ( $\mathrm{p}=0.003)$. At the $3^{\text {rd }}$ and $6^{\text {th }}$ months, there was no swelling. The intensity of swelling was higher in 24 hours as compared to 7 days in the study group which was statistically significant ( $p<0.05$ ) (Figure 1). In the study group, it was 127.97 and 120.5 was in the control group. The study group was higher as compared to the control group and it was statistically significant ( $p$ $>0.05$ ) (Figure 2).

\begin{tabular}{|l|c|c|c|}
\hline Duration & $\begin{array}{c}\text { Study Group } \\
\text { (Mean) }\end{array}$ & $\begin{array}{c}\text { Control Group } \\
\text { (Mean) }\end{array}$ & p-value \\
\hline 24 hours & 5.37 & 4.87 & 0.18 \\
\hline 7 days & 1.73 & 1.5 & 0.15 \\
\hline 3 months & 0 & 0 & - \\
\hline 6 months & 0 & 0 & - \\
\hline
\end{tabular}

Table 1: Comparison of pain scores between study and control group in relation to the duration using Mann-Whitney $U$ test.

\section{Discussion}

Healing of extraction socket after tooth removal involves retention of the blood clot followed by a sequence of events that lead to changes in the alveolar process in a three-dimensional fashion

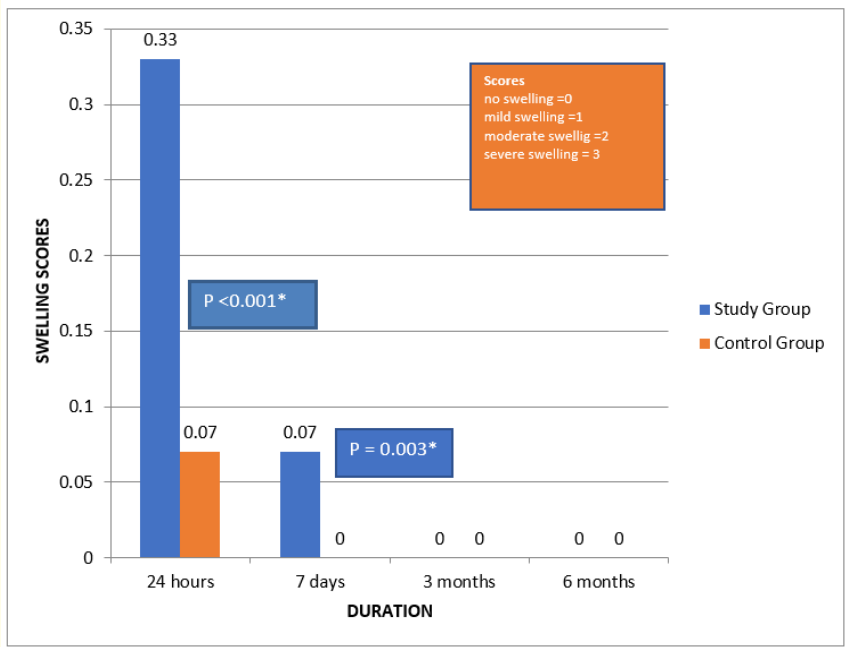

Figure 1: Comparison of mean swelling intensity scores between study and control group in relation to the duration using Mann-Whitney U test.

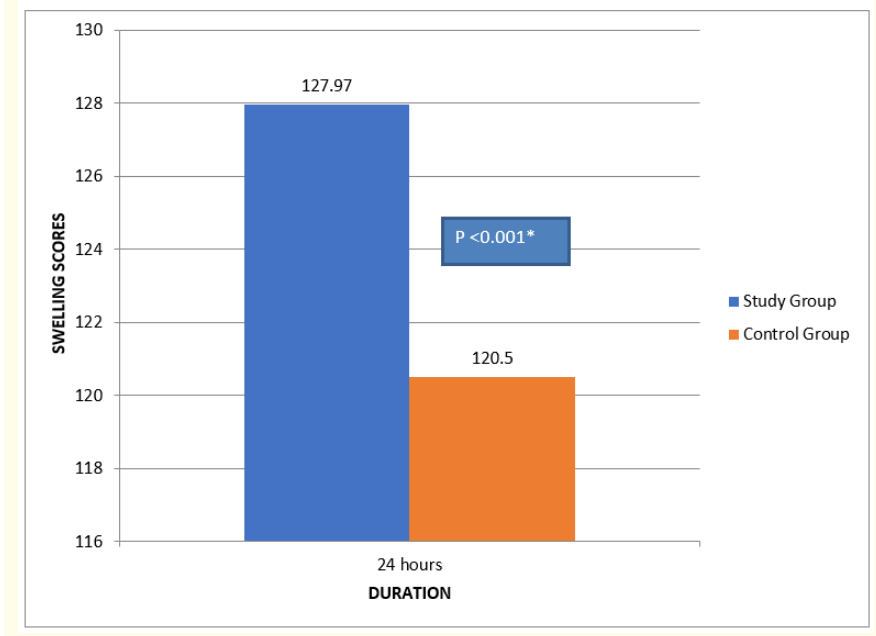

Figure 2: Comparison of mean bone density pixels between study and control group using Mann-Whitney U test.

[7]. This normal healing event results in a minimal loss of vertical height (around $1 \mathrm{~mm}$ ), but a substantial loss of width in the buc- 
colingual plane (4 - $6 \mathrm{~mm}$ ). During the first three months following the extraction, the bone loss seen is significant and may result in both hard and soft tissue deformity affecting the ability to restore the site with acceptable aesthetics [8].

Procedures that reduce the resorptive process have the potential to eliminate secondary surgery for site preservation, which can be used for dental implant placement or the fabrication of a fixed or removable prosthesis. The key element is prior planning by the dentist to act at the time of extraction to prevent the collapse of the ridge due to the loss of alveolus [9]. Several techniques have been employed as ridge preservation procedures which involve the use of bone grafts or barrier membranes to provide a better restorative outcome. Several grafting materials like autografts, allografts, xenografts have been introduced for socket preservation [10].

An autogenous graft is considered the gold standard amongst graft materials. Though autogenous grafts have excellent graft acceptance, they are associated with host site morbidity and limited availability of the tissue [2]. In this study, they evaluated the efficacy of autogenous tooth as graft material in the mandibular third molar extraction sockets and have also assessed the potential use of the material as an alternative for autologous bone and other graft materials. Also, the hard tissue healing potential of this material has been studied.

Murata., et al. [5] prepared autogenous DDM from the non-functional vital tooth. Under liquid nitrogen cooling, the molars were crushed mechanically. The crushed tooth granules were then decalcified completely in $0.6 \mathrm{~N} \mathrm{HCl}$ solution. The pain was, purely a subjective sign was recorded by the Numeric Rating Scale for quantification of pain [11]. In the present study, postoperative pain was compared between two groups which did not show any significant change, suggesting that the choice of bone graft material did not affect the postoperative pain or swelling.

The scores for density were assessed radiographically, in which those for the study group were higher as compared to that of the control group at the end of the $7^{\text {th }}$ day, $1^{\text {st }}, 3^{\text {rd }}$ and $6^{\text {th }}$ month. The difference was statistically significant due to the presence of tooth used as bone graft material in the extraction socket but, the actual difference in the overall density of bone was not radiographically significant. The actual bone density at the end of the $3^{\text {rd }}$ and $6^{\text {th }}$ month post-operative showed better results in the study group as compared to the control group.
Based on the results and observations, the following limitations of this study have been noted. Due to the very slow replacement of dentin, a follow-up period of more than 6 months would be more appropriate for evaluation of the stability of autogenous tooth as graft material. Histological analysis should be included to emphasize the results and arrive at a better conclusion.

Autogenous tooth processed as graft material should be considered as the gold standard for socket preservation, bone augmentation in sinuses, or filling bone defects. Furthermore, being autogenous leads to the absence of antigenicity, hence, enhances the bone remodeling capabilities. With properties such as quick bone formation and cheaper cost, autogenous tooth as graft material can be considered as a boon to dentistry [12].

\section{Conclusion}

Significant improvement in wound healing and increase in bone density highlights the use of autogenous tooth as a graft material in inducing and accelerating hard tissue regeneration following tooth extraction. The usage of the tooth as a graft material is simple, costeffective, and requires no special armamentarium and infrastructure for preparation. Autogenous teeth were used as graft materials in lower third molar extraction sockets and clinical as well as radiographic features were evaluated.

\section{Conflict of Interest}

None.

\section{Source of Funding}

None.

\section{Bibliography}

1. Horowitz R., et al. "A review on alveolar ridge preservation following tooth extraction". The Journal of Evidence-Based Dental Practice 12.3 (2012): 149-160.

2. Kim YK., et al. "Development of a novel bone grafting material using autogenous teeth". Oral Surgery, Oral Medicine, Oral Pathology, and Oral Radiology 109.54 (2010): 496-503.

3. Murata M., et al. "Human dentin as novel biomaterial for bone regeneration". In: Pignatello R, editor. Biomaterials - Physics and Chemistry. Croatia: In Tech (2011): 127-140. 
4. Ogundipe OK., et al. "Can autologous platelet-rich plasma gel enhance healing after surgical extraction of mandibular third molars". Journal of Oral and Maxillofacial Surgery 69.9 (2011): 2305-2310.

5. Murata M., et al. "Acid-insoluble human dentin as carrier material for recombinant human BMP-2". Journal of Biomedical Materials Research Part A 100.3 (2012): 571-577.

6. Jahangiri L., et al. "Current perspectives in residual ridge remodeling and its clinical implications: a review". Journal of Prosthetic Dentistry 80.2 (1998): 224-237.

7. Ajay Vikram Singh and Sunita Singh. "Tooth Autograft: Use of human tooth as a novel biomaterial for bone regeneration". Advances in Biomaterials Science and Biomedical Applications 13.3 (2015): 1-6.

8. Kabir MA., et al. "Autogenous Demineralized Dentin Graft for Third Molar Socket Regeneration - A Case Report". Dentistry 5 (2015): 343.

9. Kim YK., et al. "Autogenous Tooth Bone Graft Block For Socket Preservation: A One-Stage Technique". Dentistry 7.2 (2017): 414.

10. Tomlin EM., et al. "Ridge preservation for implant therapy: a review of the literature". The Open Dentistry Journal 8 (2014): 66-76.

11. Ogundipe OK., et al. "Can autologous platelet-rich plasma gelenhance healing after surgical extraction of mandibular third molars?" Journal of Oral and Maxillofacial Surgery 69.9 (2011): 2305-2310.

12. Ritchie HH., et al. "Six decades of dentinogenesis research. Historical and prospective views on phosphophoryn and dentin sialoprotein". The European Journal of Oral Sciences 106.1 (1998): 211-220.

\section{Assets from publication with us}

- Prompt Acknowledgement after receiving the article

- Thorough Double blinded peer review

- Rapid Publication

- Issue of Publication Certificate

- High visibility of your Published work

Website: www.actascientific.com/

Submit Article: www.actascientific.com/submission.php

Email us: editor@actascientific.com

Contact us: +919182824667 